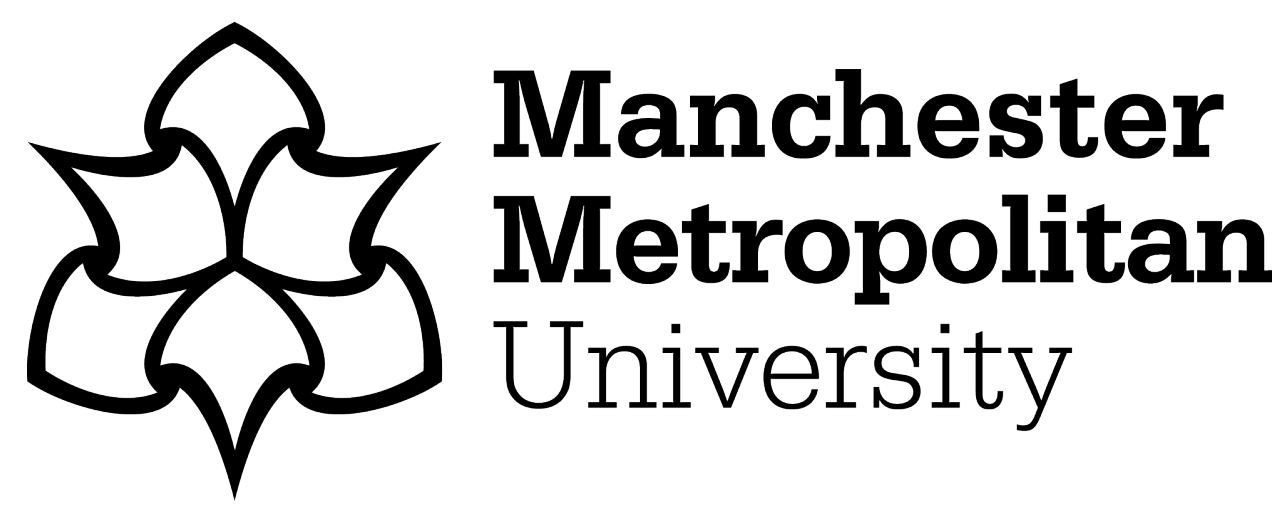

Thomas, Christopher ORCID logoORCID: https://orcid.org/0000-0002-03462417 (2022) Spinoza on Melancholy and Cheerfulness. Dialogue, 61 (1). pp. 161-176. ISSN 0012-2173

Downloaded from: https://e-space.mmu.ac.uk/627993/

Version: Accepted Version

Publisher: Cambridge University Press (CUP)

DOI: https://doi.org/10.1017/s0012217321000135

Please cite the published version 


\section{Spinoza on Melancholy and Cheerfulness}

\section{CHRISTOPHER THOMAS Manchester Metropolitan University}

ABSTRACT: Spinoza's philosophy is often celebrated for its strong anti-normative current. Spinoza argues, for instance, that good and bad do not indicate anything positive in things, and that affects are always particular to the situation in which they arise. And yet Spinoza argues that melancholy is "always evil," and cheerfulness "always good," thus problematizing a key metaphysical principle of his system. Turning to select sections in the Ethics and Theological-Political Treatise, this article offers a reading of these two problematic affects before connecting Spinoza to recent work on early modern melancholy that conceptualizes it as an 'assemblage.'

RÉSUMÉ : La philosophie de Spinoza est souvent célébrée pour son fort courant antinormatif. Spinoza soutient, par exemple, que le bien et le mal n'indiquent rien de positif dans les choses, et que les affects sont toujours particuliers à la situation dans laquelle ils surviennent. Et pourtant, Spinoza soutient que la mélancolie est "toujours mauvaise " et la gaieté "toujours bonne ", problématisant ainsi un principe métaphysique clé de son système. Prêtant attention à certaines sections de l'Éthique et du Traité théologicopolitique, cet article offre une lecture de ces deux affects problématiques, avant d'établir un lien entre Spinoza et des travaux récents sur la mélancolie aux débuts de l'époque moderne, qui la conceptualisent comme un " assemblage ".

Keywords: Spinoza, affects, melancholy, cheerfulness, assemblage

\section{Introduction}

There are two things that are puzzling regarding Spinoza's treatment of the affects melancholy (melancholia) and cheerfulness (hilaritas). Firstly, Spinoza holds that, whilst all affects are always particular to their situation, melancholy and cheerfulness are altogether different and appear as good or bad without regard to circumstance. For instance, whilst the affect pain can be good and enhance a person's power to strive, insofar as it takes away a greater evil, melancholy is "always evil" (IVP42). ${ }^{1}$ According to Spinoza, then, whilst in certain circumstances the affect pain can be good for an individual's striving, there are no circumstances under which melancholy could ever be considered good. The reverse also holds for cheerfulness, which Spinoza tells us is "always good" and can under no circumstances lead to a diminishment in a person's power to strive (IVP42).

As is well known, it is central to Spinoza's naturalistic philosophy that he denies the intrinsic value of things, and this includes the value of objects as much as it does the value of affects. Indeed, various authors place great emphasis on this aspect of Spinoza's work, situating his theory of affects in a strong anti-normative current that positions affects as particular to the affected individual and the time and space in which they relate. ${ }^{2}$ Hence, the

\footnotetext{
${ }^{1}$ I follow the standard abbreviations for the Ethics, whereby IP12Dem denotes the Demonstration to Proposition 12 of Part 1 of the Ethics. Therefore, the Physical Digression after IIP13 is referenced IIPD followed by the specific lemma, axiom, or postulate to which the citation refers. All references to the Ethics are from Spinoza, Ethics, in A Spinoza reader: The Ethics and other works.

${ }^{2}$ See, for instance, Gatens \& Lloyd (specifically, pp. 100-107), Sharp (specifically, Chapter 6), and most recently Lucchesse for excellent accounts of the strong anti-normative current in Spinoza's philosophy.
} 
claim that melancholy is always evil and that cheerfulness is always good should puzzle any reader of the Ethics. This is the first sense in which melancholy and cheerfulness appear, for Spinoza's philosophy, problematic at worse and puzzling at best.

Secondly, Spinoza's claim that cheerfulness, and by implication its antonym melancholy, are "more easily conceived than observed" (IVP44Schol) sets them apart from the other kinds of affects in the Ethics and appears to place them in a class of their own. Spinoza writes at length that the perceptions of the imagination, as the first and primary form of knowledge, are the easiest way to accrue (inadequate) knowledge about the world, and to this extent all knowledge of objects or affects should be easiest to accrue through perception and observation rather than through active forms of reasoning. Given this, what does it reveal about the particularity of melancholy and cheerfulness that they are more easily conceived than observed? What is unique to these affects that leads Spinoza to make such an ambiguous claim, and why do these particular affects appear to break the standard epistemological rules of Spinoza's theory of the affects?

Drawing on relevant sections of the Ethics, this article offers a reading of these two problematics that surround Spinoza's treatment of melancholy and cheerfulness. I argue that the normativity that Spinoza ascribes to melancholy aims only to give a name to that which is everywhere recognized but nowhere fixed in terms of its content and the form it takes. Thus, I suggest that, like his treatment of good and evil, Spinoza chooses to retain a normative description of melancholy and cheerfulness because it allows us to name an affective state that is always and everywhere recognizable, but at the same time without a fixed and easily representable content. This gives rise to affects that are difficult to imagine, understand, and represent with any adequacy, but that nevertheless must be retained in a vocabulary of the affects in order to give structure and direction to human life.

\section{The 'Wholeness' of Melancholy and Cheerfulness}

The history of melancholy is one of competing definitions, representations, and confusions. In 1621, Robert Burton composed a now famous tome on a disease that he noted was so frequent, and that occurred so often that few did not feel the smart of it (Burton, 1978, p. 120). This disease, so frequent in early modern times and that affected so many that few did not fall under its mist, is the disease of melancholy, and the book that begins with these words is Burton's The Anatomy of Melancholy. With his book, Burton diagnoses a condition as common as it was contested: melancholy was everywhere present, but nowhere agreed upon as to its form. The European early modern period was saturated with melancholics; with artistic, literary, and theatrical representations of melancholy, with astrological and medical explanations of melancholy, and, finally, with philosophical discussions of both the disease (Hippocrates) and temperament (Aristotle) of melancholy. Melancholy was so pervasive in early modern Europe that, as Burton wrote, few did not feel the smart of it.

But again, melancholy's ubiquity did not mean that it was easily identifiable, or without contest as to its causes and symptoms. As ever, it is William Shakespeare to whom we can turn in order to express the feeling of the day. This is Jacques explaining and detailing his own melancholy in Shakespeare's As You Like It:

I have neither the scholar's melancholy, which is emulation; nor the musician's, which is fantastical; nor the courtier's, which is proud; nor the soldier's, which is ambitious; nor the lawyer's, which is politic; nor the lady's, which is nice; nor the lover's, which is all these; - but it is a 
melancholy of mine own, compounded of many simples, extracted from many objects, and, indeed, the sundry contemplation of my travels, which, by often rumination, wraps me in a most humorous sadness. (Shakespeare, 1996, IV. I) ${ }^{3}$

Jacques melancholy is his own; it does not have one cause but is extracted from many simples and many objects, and is a result of his various experiences that cause him to be wrapped in a most humorous sadness. And so, if Burton tells readers that melancholy is all-pervasive in early modern culture and society, Shakespeare tells us that it is equally confused and contested, with everyone claiming a melancholy of her own. ${ }^{4}$

Given the ubiquity of melancholy in the early modern period, it is likely that Spinoza was aware of its various representations and the problems it raises as an affect in need of explanation. Indeed, it is possible to point to places where Spinoza himself reveals at least a cursory knowledge of the history of melancholy's complex representation. For instance, in both the Theological Political Treatise (TTP) and the Ethics, Spinoza shows himself to be aware of the deeply ingrained historical and cultural connection between melancholy and its cure in music. In the chapter of the TTP concerned with prophecy Spinoza refers to King Saul's melancholy and his attempt to ease it by the summoning of a musician (David) (TTP, Chapter 1, p. 22)..$^{5}$ This is a well-known story of the Old Testament, which has been widely represented in a variety of artistic forms. ${ }^{6}$ Indeed, the correlation between music and melancholy that Spinoza refers to in the TTP is also taken up and widely accepted in the historical literature on the subject. As Raymond Klibansky, Erwin Panofsky, and Fritz Saxl show, it was frequently said of those who have an illness "like King Saul's" that they are to be played music as a therapy for their illness (see Klibansky, Panofsky, \& Saxl, 1964, pp. 46, 81, 291). Furthermore, in the Preface to Part IV of the Ethics, in the midst of arguing that good and evil refer to nothing positive in the thing they are ascribed to, Spinoza once again recites the historically precedent claim that music is good for one who is melancholy. These passages therefore suggest that Spinoza had at least a passing understanding of the cultural-religious explanations of melancholy and its therapeutic cure in music and the arts more broadly.

And yet, despite demonstrating an awareness of melancholy's historical relationship to music, Spinoza fails to take up the affect in any detail and only refers to it six times in the Ethics and twice in the TTP. ${ }^{7}$ Its definition is given in IIIP11Schol and then re-affirmed in Definition Three of the Definitions of the Affects. But most important of all these fleeting

\footnotetext{
3 Jacques' detailing and parodying of the complexity of his own melancholy in Shakespeare's As you like it, Act IV Scene I.

${ }^{4}$ Whilst both Burton and Shakespeare are writing in an Anglophone context, the 'epidemic' and proliferation of melancholy clearly extended into mainland Europe, with Burton citing German, French, and Italian sources. On this, see Gowland, p. 80.

${ }^{5}$ References to the Theological-political treatise are from Spinoza. Citations are referenced by the chapter number, followed by the page number of the 2007 Israel \& Silverthorne edition.

${ }^{6}$ See Samuel Book 1, 16: 14-23, and for visual representations of David and Saul, see Rembrandt van Rijn's Saul and David (1655-1660). Likewise see the representations of music as a therapy for melancholy in plates 67 and 70 of Klibansky, Panofsky, \& Saxl. It should be noted that, whilst is no evidence that Spinoza ever met Rembrandt, despite living very close to him in Amsterdam, they did have a tenuous link through Menasseh ben Israel, and would have perhaps known of each other's work via this mutual associate. On the RembrandtSpinoza connection, see Nadler, pp. 76-79.

${ }^{7}$ See IIIP11Schol, IIIDef3, IV Preface, IVP35Schol, IVP42, IVP45Schol, TTP Chapter 1, p. 21, TTP Chapter 1, p. 22.
} 
references is what Spinoza affirms of it and its antonym cheerfulness when defining them in IIIP11Schol:

The affect of joy which is related to the mind and body at once I call pleasure or cheerfulness, and that of sadness, pain or melancholy.

But it should be noted [NS: here] that pleasure and pain are ascribed to a man when one part of him is affected more than the rest, whereas cheerfulness and melancholy are ascribed to him when all are equally affected. (IIIP11Schol)

In this Scholium melancholy and cheerfulness are defined at the same time as the primary affects of joy and sadness, and before the definitions of the other affects. By defining them alongside the primary affects of joy and sadness, Spinoza privileges both melancholy and cheerfulness, and suggests that they are indicative of a wider kind of affect that relate to mind and body alike. But, more importantly than this, Spinoza continues that not only are melancholy and cheerfulness the kinds of affect that affect both the mind and body, but that they also are affects that affect all the parts of an individual equally. And so, whilst melancholy and cheerfulness are derived like all the other affects from sadness and joy, respectively, they differ in the extent and scope of their affective power. Put differently, whilst melancholy and cheerfulness are contrasted with pain and pleasure as other types of affections of sadness and joy, the principal difference between melancholy and pain, cheerfulness and pleasure, is that, whereas pleasure and pain are affects that affect one part of the individual more than the rest, melancholy and cheerfulness affect all the parts of an individual equally.

To this extent, pleasure and pain appear as affects that disproportionately affect, and their presence is always felt acutely in a particular part of the wider composite individual. Indeed, it could be said, following Jonathan Bennett, that these kinds of affects are partial affects (Bennett, 1984, p. 312). On this terminology, the affect pleasure would be the partial increase or decrease in the affected individual's ability to act insofar as only one part of that individual alters its power. ${ }^{8}$ It follows from Bennett's terminology that if pain and pleasure are partial affects, then melancholy and cheerfulness ought then to be referred to as whole affects, since they are of such a kind that they affect all the parts of an individual equally. Indeed, the presence of melancholy or cheerfulness in the affected individual is what might be described as an all-encompassing affect that leaves no part of the individual unaffected. And so, whilst Spinoza gives pain or pleasure as affects that affect only one part of the body and because of this acuteness leave unaffected the various other parts of the composite individual, melancholy and cheerfulness are altogether different and are explained as affects that are entirely enveloping in their affective power.

According to Bennett's theory of 'partial affects,' because an affect of pain is only related to one part of the individual more than the rest, then the parts of the body left unaffected by pain would therefore be open to different affects, such as when one is affected with anger over the specific pain one might feel in one's body, or when one is affected with gladness whilst still being in pain. For Spinoza, then, an individual may have

\footnotetext{
${ }^{8}$ Here it should be noted that the partial affect of pleasure might either be good or bad for the whole individual. Hence, in IVP45, Spinoza claims that, whilst pleasure is most often a modification of the affect joy, and therefore an increase in an individual's power, if it becomes "excessive," then it will be detrimental and "evil" for an individual's striving (IVP45).
} 
partial affects that only affect a particular part of her, leaving the remainder of her constituent bodies open to entirely different and even contradictory affects. And yet, whilst this is true of pain and pleasure, melancholy and cheerfulness are altogether different kinds of affects, for in their case no part of the affected individual will be unaffected. In other words, when an individual is affected with either melancholy or cheerfulness, there is no part of the body or idea in the mind that remains unaffected by the diminution or increase in power that is the affect of melancholy or cheerfulness. This means that, when affected with melancholy or cheerfulness, there are no parts of the individual from which one might undergo a different affect unrelated to melancholy or cheerfulness; melancholy and cheerfulness are all-inclusive, and the melancholic individual will be entirely subsumed by melancholy's affective power even in the face of other affects.

Here Spinoza conforms to the historically precedent idea of melancholy as entirely enveloping such that all the perceptions of the melancholic are shaded with a saturnine hue that render the subject in a state of stasis. Some have suggested that this 'incapacitating' aspect of melancholy derives from its Aristotelean side. ${ }^{9}$ In the face of an infinity of things that need to be explained and ordered, so the thinker becomes overwhelmed, incapacitated, and powerless of further thinking that isn't coloured with the melancholic posture. Indeed, Michael Camille sums this up well when he suggests that Albrecht Dürer's Melancolia I, often described as the first image of the melancholic posture (see Daniel, 2013 , p. 39), depicts a "[...] winged genius incapacitated in the face of a neurotic need for knowledge" (Camille, 1986, p. 59). Like Aristotle before him, Dürer depicts the melancholic as entirely overwhelmed by a pursuit for knowledge and thus entirely enveloped in an affective state that permits of no other affects, and that ultimately leads to a radical stasis of both body and mind.

In a different but nerveless similar vein, Jacques' detailing of his melancholy in Shakespeare's As You Like It also hints at the all-encompassing capacity of melancholy when he states: "[...] it is a melancholy of mine own, compounded of many simples, extracted from many objects, and, indeed, the sundry contemplation of my travels, which, by often rumination, wraps me in a most humorous sadness" (Shakespeare, 1996, IV. I). With this line, Jacques articulates his melancholy as "compounded from many simples," "extracted from many objects," and which leads him to be wrapped "in a most humorous sadness" (Shakespeare, 1996, IV. I). In the melancholic despair, there is no single cause or object of one's melancholy, but the melancholic disposition is perpetuated from the many simples and many objects that one encounters in one's day-to-day relations. In the same vein that Spinoza conceives of the affect melancholy as being all-encompassing, so for Jacques, melancholy is an affect so pervasive that all the relations one undergoes become new sources of one's melancholy, leading to the individual being 'wrapped' in a totalizing sadness.

\footnotetext{
${ }^{9}$ As well as the dominant Hippocratean concept of melancholy as a disease of the body with physiological roots, Aristotle adds that those who are outstanding in the fields of philosophy, politics, poetry, or the arts, and who are "unlike the majority of people," are those who tend towards the melancholic disposition (Aristotle, p. 1501). Hence, in Problem One of Book XXX of his Problems, Aristotle states: "Why is it that all those who have become eminent in philosophy or politics or poetry, or the arts are clearly of an atrabilious temperament, and some of them to such an extent as to be affected by diseases caused by black bile, as is said to have happened to Heracles among the heroes?" (Aristotle, pp. 1498-1499 [953a110-20]). Here Aristotle adds to the Hippocratean concept of melancholy as a disease of the body with physiological roots, with the claim that melancholy afflicts those of a certain character, nature, or temperament, thereby adding to melancholy's historical representation as that which overwhelmingly afflicts the creative and the learned.
} 
This all-inclusive affective capacity is the extent of melancholy as an affect, and the consequences for the individual who suffers it, Spinoza tells us, are great. By having all of its constituent parts negatively affected at once, an individual is altered in a fundamental way. In IVP42, Spinoza begins to explain the power of such all-inclusive affects by telling readers that "Cheerfulness cannot be excessive, but is always good; melancholy, on the other hand, is always evil" (IVP42). Spinoza supports this claim by appealing to what happens to individuals when all of their constituent parts are affected with melancholy or cheerfulness at once. Insofar as it relates to the body, cheerfulness, Spinoza asserts, affects all the parts of the body equally and in this way increases the body's power of action so that all its parts maintain the same proportion of motion and rest to one another. Contrasted to this is melancholy, which has the contrary effect of restraining and diminishing the body's power to act, and therefore negatively altering the proportion of motion and rest between an individual's constituent parts (IVP42Dem). Moreover, Spinoza goes so far as to say:

Melancholy [...] is a sadness, which, insofar as it is related to the body, consists in this, that the body's power of acting is absolutely diminished or restrained. And so (by P38) it is always evil. (IVP42Dem, emphasis added)

According to Spinoza, melancholy has the effect of absolutely diminishing the body's power of acting, and it is through this radical and absolute altering of the ratio of motion and rest between the parts of a body that makes melancholy always evil. The fact, then, that for Spinoza melancholy is always evil and cheerfulness is always good, whilst in certain circumstances pain can be good and pleasure can be bad (IVP43), demonstrates the power and uniqueness that Spinoza affords to the affects melancholy and cheerfulness.

\section{The Epistemic Status of Melancholy}

In part II of the Ethics, Spinoza introduces the three ways that we can come to attain knowledge about Nature. As is well known, Spinoza's three kinds of knowledge span imagination and opinion, reason, and what he defines as knowledge gained by intuition (IIP40ScholII). These three kinds of knowledge describe the ways that human beings more or less adequately come to understand themselves and the world. The first kind of knowledge that Spinoza identifies is knowledge accrued through affective encounter, through sensation. This affective understanding of things gives rise to knowledge about the world that is particular to the subject of those affects, hence Spinoza describing it in the vernacular as "opinion" (IIP40ScholII). This is the way that human beings most often come to understand the world. Even without trying, we accrue ideas about things through imaginative forms of knowledge, and it is for this reason that imagination is the way that men, "by nature" (IApp), come to have their first (inadequate) ideas regarding the order of things. Human beings perceive, sense, and imagine the world before they begin to actively reason about the world, and because of this, such knowledge is always partial and confused. We know through imagination before we actively come to use the power of reason, or intuition, and because of this, we must make a special effort to go beyond the image of the world we've developed according only to our affective encounters. Imaginative knowledge is, then, the easiest way to know things about the world, with a rational understanding of the world requiring at least an effort on the part of thinking subjects to move beyond an understanding of the way things affect them, to an understanding of the causal nexus within 
which these affective encounters take place. To actively reason about things requires effort, and because of this, it is rare in human beings.

With this, Spinoza sets out an order of knowledge about the world with the imagination being the most frequent way we come to know things about the world, ourselves, and the affects by which we are daily torn. And yet Spinoza nevertheless calls this order of things into question when he discusses cheerfulness in IVP44Schol, and once again distinguishes it from the other affects. To quote:

Cheerfulness, which I have said is good, is more easily conceived than observed. For the affects by which we are daily torn are generally related to a part of the body which is affected more than the others. Generally, then, the affects are excessive, and occupy the mind in the consideration of only one object so much that it cannot think of others. (IVP44Schol, emphasis added)

In this quotation, Spinoza refers only to cheerfulness, and before I develop it, I would like to address the objection that melancholy and cheerfulness may not have the same relationship of mirrored but opposite affects that joy and sadness, or pleasure and pain do. In other words, the question becomes: when Spinoza speaks of one, is what he says always true of the other? ${ }^{10}$ In both IIIP11Schol and IVP42, Spinoza offers his technical definitions of melancholy and cheerfulness. In IIIP11Schol, they are theorized alongside one another as affects that function in the same manner as joy and sadness, namely, as affects that indicate a particular transition to a greater or lesser power of acting. Here Spinoza is clear in his definition of joy and sadness as indicating the same but opposing transitions of an individual's striving, and the inclusion of melancholy and cheerfulness immediately following these definitions suggests that he considers them in the same way. However, whilst joy and sadness indicate the mind's passage to a greater or lesser perfection, pleasure and cheerfulness, pain and melancholy are slightly different changes to an individual's power: "The affect of joy which is related to the mind and body at once I call pleasure or cheerfulness, and that of sadness, pain or melancholy" (IIIP11Schol). Here Spinoza defines pleasure at the same time as pain, and melancholy at the same time as cheerfulness, as opposing affects that affect both the mind and body at once. And yet, as previously noted, their difference lies in the way they affect the individual's constituent parts, with pain and pleasure occurring when one part of an individual is affected more than the rest, whilst melancholy and cheerfulness occur when all the parts of both the mind and body are equally affected. Spinoza's treatment of melancholy and cheerfulness as a species of joy and sadness, and as offering an instance of pain and pleasure when all the parts of the body are equally affected, strongly suggests that he thinks of these two affects as being related in the same manner as joy and sadness, and pleasure and pain. In addition to this, he continues to treat them together in IVP42 where he notes that cheerfulness is always good, whilst melancholy is always evil, seemingly normative claims that once again suggest that they are a particular class of affect that relate to one another as opposites. Given this, it is not a stretch to suggest that even when Spinoza takes up one without the other, such as in his treatment of cheerfulness in IVP44Schol, what he says about one can nevertheless also be said, though in reverse, about the other. To this end, when in IVP44Schol Spinoza

\footnotetext{
${ }^{10}$ I thank an anonymous reviewer for pointing out this objection.
} 
suggests that cheerfulness is "more easily conceived than observed," I take this claim to be not only about cheerfulness, but about melancholy too. Hence, I take it that whenever Spinoza is talking about melancholy or cheerfulness, he is likewise talking about its other, except that one is related to joy and the other to sadness.

To return to the Scholium in question, we can see that IVP44Schol's claim that cheerfulness is "more easily conceived than observed" appears to contradict a basic principle of Spinoza's epistemology wherein knowledge gained through imagination is the easiest way to accrue knowledge about the world. Nonetheless, Spinoza begins to offer an explanation of it by way of another claim demonstrated earlier, namely, that the "general affects" by which we are "daily torn" are those that relate to one part of the body more than the others, and that cause the mind to be occupied "in the consideration of only one object so much so that it cannot think of others" (IVP44Schol). Here Spinoza is arguing that the 'partial affects' occupy the mind with only a single image of the perceived cause of that affect. Hence, Spinoza continues that the general affect of greed is easily perceived, and hence occupies the mind excessively in this singular perception, because it has but a single object and therefore an easily determinable cause: the idea of money (IVP44Schol). Contrary to these general kinds of affects, melancholy's ubiquity means that it is very difficult to determine its origin to a single cause or object, and because of this is very difficult to perceive. Here, Spinoza suggests that, whilst the mind is occupied with the consideration of only one kind of object when its body is affected with pain, the mind is conversely occupied in the consideration of many kinds of objects when it is affected with melancholy or cheerfulness. In other words, in the melancholic state, the mind is not, as with the general and partial affects, occupied by the image of only one body that is seen as the affect's cause, but is rather besieged by many different bodies each of which contribute to the allencompassing melancholic disposition. And this goes some way to explaining Spinoza's puzzling claim that melancholy and cheerfulness are more easily conceived than perceived: the multiplicity of bodies involved in the perception of the affect melancholy means that the imagination simply struggles to perceive the distinct causal instances of the origin of the affect of melancholy.

The claim that the multiplicity of causes involved in the affect melancholy (and cheerfulness) renders it difficult for the imagination to observe can be explained more clearly if, firstly, the reader takes Spinoza's contrast of conception and observation to be equally a contrast of intellect and imagination, and secondly, if we turn to what Spinoza asserts of the imagination's power, or lack of power, in his thesis on universals in IIP40Schol1. In IIP40Schol1, Spinoza explains the existence of universals by appealing to the limitation of the body and the limitation of its idea, the mind. Because the body is finite and the imagination's power is correspondingly limited, an individual is capable of forming distinctly only a certain number of images at any one time. When the number of images a human being can form at once is surpassed, the imagination fails to distinguish between the individual bodies consequently rendering them under a single, universal determination such as Man or Dog. According to Spinoza, the power to form distinctly the causes of the images one is affected with is surpassed when the affected individual is overloaded with perceptions. The idea I have of 'Man' is formed because I am unable to consolidate each image of each man that is impressed upon my body by my various experiences of individual men; I simply have undergone too many experiences of individual men and my power to recall the image of each of them is not great enough. By contrasting melancholy to the 'general affects' that occupy the mind with the image of only one object, Spinoza is 
suggesting that melancholy's cause is located in many distinct external objects, and that, in the melancholic state, the mind is overloaded in the consideration of these many different images. In this way, the affect melancholy is difficult to perceive because of the imagination's limited power to consolidate the multiplicity of heterogeneous causes that give rise to it. And so melancholy will be difficult to perceive precisely because individuals lack the perceptive power to consolidate the multiple causes of melancholy into a universal image that stands in for each of the images that give rise to it.

Likewise, this is also why melancholy is more easily conceived via the intellect, for the power of reason does what the power of imagination fails to do: reason is able to consolidate melancholy's complex causal origins and determine it as the affect melancholy. In this case, when one tries to imagine melancholy, one fails to grasp it in any adequacy, for it can entail so many divergent causes that any form through which it might be represented ultimately fails to capture its composite nature. And so it is possible to see why, by nature of its implication in many bodies at once - both internal to the affected body (IIIP11Schol) and external (IVP44Schol) - melancholy is more easily conceived than observed, for the imagination simply struggles to attain the power it requires so as to consolidate its diverse multiple causes into a single determinable subject, namely, melancholy.

For Spinoza, melancholy is always implicated in many external bodies at the same time and it will constantly shift in response to the affected individual's changing milieu. Because melancholy is entirely enveloping, the melancholic perpetually turns each of the bodies she has relations with into a new source of her melancholy therefore perpetually redrawing the boundaries of her own, specific melancholy. In this way, Spinoza's idea of melancholy as particularly enveloping and difficult to perceive fits with the historical understanding of melancholy as an affliction with diverse and variable sources, and whose cause is hard to trace to a singular thing. ${ }^{11}$ As the melancholic encounters new bodies, their particular melancholy, as Jacques puts it in As You Like It, will mutate along with their continually changing environment.

Melancholy and cheerfulness are, then, a kind of affect that is involved in many varying bodies both internal and external to the individual. In this sense, it is possible to suggest that melancholy and cheerfulness are, for Spinoza, uniquely powerful affects and as such require a particularly complex process of understanding to be able to determine anything about them with any adequacy.

\section{Melancholy and Cheerfulness: Normative Affects?}

But whilst melancholy and cheerfulness might be particularly unique kinds of affects in virtue of their multifaceted composition and related ability to affect all the parts of an individual at once, Spinoza's discussion of them doesn't serve to fully explain his claim that melancholy is "always evil" and cheerfulness is "always good" (IVP42). According to Michael Lebuffe, Spinoza's lack of discussion of melancholy and its antonym cheerfulness provides a real problem for his overall ethical theory because he appears to give them the status of affects that have an objective value (Lebuffe, 2009, pp. 216-218). Put differently, Spinoza holds that melancholy and cheerfulness are affects that are bad or good in themselves,

\footnotetext{
${ }^{11}$ Indeed, this idea of melancholy resonates with Freud's explanation of the melancholic disposition in his essay, Mourning and melancholia. For Freud, mourning is a grief that comes with a determinable cause, and is thus normal and healthy, whereas melancholy is a feeling of grief the cause of which one cannot identify or comprehend. To this end, melancholy is, for Freud, a condition without a single determinable cause, and is thus pathological. On this, see Freud.
} 
which flies in the face of the anti-normative current that is often said to guide his entire philosophy.

The absence and hostility to normativity in Spinoza's philosophy is often attributed to his denial of any and all forms of teleology, which in turn is a consequence of the immanent ontology that grounds his philosophy. For Spinoza, there is no end set before Nature, and there are no ends in Nature, for there is nothing external to Nature that could imbue it with a direction, and nothing in Nature that is not subject to necessity. In a recent article, Filippo del Lucchese stakes out the debate concerning Spinoza's treatment of teleology in an attempt to return the problem to its most basic constituents. Lucchese argues that recent Anglophone readers have imbued Spinoza's philosophy with an element of teleology that threatens the radicalism and originality of his anti-normative position (Lucchese, 2020, p. 149). He argues that, whilst Spinoza makes explicit his denial of all forms of teleology in the Appendix to Part One of the Ethics, commentators have sought to return it to Spinoza's system not at the metaphysical level, but at the level of moral psychology. Thus, commentators such as Edwin Curley maintain that, whilst Spinoza denies all forms of teleology in the metaphysical order of Nature, the human or ethical realm cannot be disconnected from teleology, for human action is bound up with a consideration of the future, a future that is seen to drive action in the form of a final cause. It is along these lines, Lucchese argues, that teleology is often introduced back into Spinoza's philosophy:

People form opinions about the future using their imagination, evaluate the possible consequences of their actions using their reason, desire what they do not possess yet, fear what they perceive as a threat, etc. In a word, humans think about and are thus affected by the idea of the future: for many scholars, this is already teleology. (Lucchese, 2020, $p$. 150)

According to Lucchese, because Spinoza took seriously the extent to which humans think about the future, and because thoughts about the future provide a motive for human action, so his ethics can be said to include a dimension of teleology. And yet, for Lucchese, this is to overlook what mode of knowledge is involved in the appeal to the future, and to confuse what Spinoza's denial of teleology is really aimed at. In the Appendix to Part One, Spinoza explains that his treatment of teleology aims to show how human beings utilize teleological thinking in order to explain Nature, despite Nature not according to fixed and final causes. To explain things in virtue of an end is a consequence of the imagination's tendency to finality (Lucchese, 2020, p. 152), which has the effect of turning Nature upside down insofar as it seeks to explain causes by their effects (IApp). But the main issue that Spinoza takes up is not concerned with the power of the imagination to imagine a future towards which our actions are directed (a power that Spinoza argues in II17Schol should, if controlled, be seen as a virtue and not a vice). Rather, Spinoza wants to guard against what thinking of the future nearly always entails, namely, the belief in the existence of final causes that are seen to drive action. It is this latter point that Lucchese wants to highlight as Spinoza's main concern: for Spinoza, teleology is not acting in view of an end perceived in the future; it is rather the giving of ontological precedence to the final cause over the efficient cause (Lucchese, 2020, p. 152).

By identifying a belief in the existence of final causes as the primary prejudice of humanity, Spinoza highlights various other prejudices that follow from this, including the 
belief that things are ascribed with an inherent value. As Spinoza explains, once human beings convinced themselves that all things were created on their account, that is to say, as means to their preservation and sustenance, they began to judge things according to their approximation to this final cause. Hence, Spinoza continues, they had to invent notions such as good, evil, order, confusion, beauty, ugliness, and so on (IApp), for it was via these notions they could rank things according to this perceived final cause. In this respect, Spinoza argues, things are often erroneously explained via their final cause, rather than from the efficient cause from which they arise. From this, it is clear that Spinoza rejects all forms of normative value, for to appeal to normativity is to affirm the ontological precedent of the effect over the final cause. As Spinoza famously notes on moral value:

As far as good and evil are concerned, they also indicate nothing positive in things, considered in themselves, nor are they anything other than modes of thinking, or notions we form because we compare things to one another. (IV Preface)

Here Spinoza makes clear that the value of good or evil we confer upon things doesn't so much indicate something in the object of judgement than it indicates a particular mode of thinking. Good and evil "indicate nothing positive in things," which is to say, they do not have an existence beyond the mind that thinks them (IV Preface). Good and evil, according to Spinoza, are prejudices, modes of the imagination that "[...] the ignorant consider the chief attributes of things" (IApp). Once again, Spinoza argues for his denial of the intrinsic value of things by referring readers back to the central tenet of his ontology outlined above: there are no ends in Nature, and therefore nothing can be said to exist for the sake of something else, such as a final cause or universal idea. The lack of ends in Nature means that nothing can be said to be nearer or further from the end at which it might be aimed. Hence, when we make the claim 'the dog is good,' we only inaccurately ascribe the property of 'goodness' to the dog, for all we are really doing is naming a relation between a particular dog and an inadequate universal idea of what an ideal dog ought to be. Indeed, Spinoza is clear that when we measure things against an apparently fixed universal, we actually measure them against something in constant flux. Far from being a static, normative relation between a contingent particular and a fixed universal, the relation of judgement between universal and particular is highly subjective for it occurs according to each person's affect (IApp). To this extent, each person's judgement of the good will differ, and each person's idea of the ideal dog will differ as much as their experience of particular dogs differs. It follows from this, Spinoza tells us, that only the ignorant take these affective relations as indicating something positive in the object of a value judgement.

What Spinoza argues regarding the value of good and evil, so he also notes of beauty and ugliness, order and confusion, perfection and imperfection, and so on. Nothing can be judged good or evil, this or that, independently of the mind that thinks it, which is equally to say nothing has intrinsic value. But such an anti-normative framework doesn't just apply to things but extends into the realm of affects too. In IVP43, Spinoza points out that not all affects that decrease an individual's power to act - not all sad affects - are evil and, likewise, not all affects that increase our power to act - not all joyful affects - are good. Affects are never intrinsically good or bad. For instance, despite Spinoza's initial definitions of pleasure and pain as affects of joy and sadness, respectively (IIIP11Schol), and thus as affects that are good and evil (IVP40), he continues to explain in IVP43 that pleasure and 
pain are not good or evil unconditionally. As he puts it: "Pleasure can be excessive and evil, whereas pain can be good insofar as the pleasure, or joy, is evil" (IVP43). Here Spinoza points out that a passive affect such as pain can be good and cause an increase in a person's ability to act insofar as it takes away a greater evil. Spinoza's technical explanation of this is premised on how the affects of pleasure and pain affect the body (and correlatively the mind). As explained above, pleasure is a 'partial affect' that affects one part of the body more than the rest. If this pleasure becomes "[...] so great that it surpasses the other actions of the body (by P6), remains stubbornly fixed in the body, and so prevents the body from being capable of being affected in a great many other ways" (IVP43), then it will be considered evil. To the extent that such an affect has a positive effect on one part of the body but a negative effect on a person's overall striving, so what is usually an affect that increases our power to strive becomes an affect that decreases our power to strive. Just like the ontology of objects that Spinoza puts forward, affects like pain and pleasure have no objective value and hence are not good or bad in themselves, but will only achieve such a value relative to a particular situation.

Melancholy and cheerfulness, however, are fundamentally different to the general affects of pain and pleasure. Because melancholy and cheerfulness affect all the parts of the individual equally leaving no part unaffected, they are given as good or bad regardless of their circumstance, a claim that threatens to contradict the particularity of the affects and therefore Spinoza's overall ethical relativism. According to Spinoza, then, the value of melancholy and cheerfulness is fixed and does not change as circumstance demands (IVP42), and this is because melancholy and cheerfulness are affects that affect all the parts of the body at once, and thus radically alter the overall striving power of the individual. But does the value that Spinoza attributes to melancholy and cheerfulness threaten his ethical relativism? By embedding the values of always good and always evil into his radically antinormative worldview, do melancholy and cheerfulness introduce a stasis to Spinoza's system that is otherwise absent?

One possible reading of the problematic nature of melancholy and cheerfulness is to turn again to how the 'good' is positioned in Spinoza's philosophy. Whilst Spinoza denies the existence of the good 'in' things because of a lack of ends in Nature, he nevertheless chooses to retain such normative language. As he explains:

But though this is so, still we must retain these words. For because we desire to form an idea of man, as a model of human nature which we may look to, it will be useful to us to retain these same words with the meaning I have indicated. In what follows, therefore, I shall understand by good what we know certainly is a means by which we may approach nearer and nearer to the model [exemplar] of human nature we set before ourselves. By evil, what we certainly know prevents us from becoming like that model. (IVPref)

Here Spinoza explains that we need to retain the words 'good' and 'evil' for they provide structure to a particular way of living that promotes flourishing for human beings. But whilst he says we should retain these words, he nevertheless continues to qualify this by stating that we should retain them in accordance with the meaning he indicates. Hence, rather than taking the good to mean a universal idea or end that a particular more or less approximates, the good should instead be thought of as a means, thereby not prioritizing 
the final cause over the efficient cause and avoiding the error of teleological thinking he cautions against. Hence, if the concept of the good traditionally indicated a final cause to which our striving is directed, it now indicates whatever functions as a means to our perseverance. The good, then, does not have any intrinsic 'content' but it is nevertheless retained as an idea so as to bring order to individual lives and direct us in the best ways of living.

In a like manner to good and evil, 'melancholy' and 'cheerfulness' might also be understood as words that name particular affective states that have specific utility for human individuals' understanding of themselves, but which nevertheless defy a clearly defined idea of what they ought to contain. Like the good, melancholy and cheerfulness are affects with no fixed content but which are nevertheless retained to describe something that is in constant flux but everywhere recognizable. Indeed, the ambiguity of what constitutes the temperament and disease of melancholy has historically led to it being seen as a kind of empty signifier, as that which stands in for all that is debilitating but which cannot be fixed or traced back to an easily identifiable and singular cause. As we have seen, Spinoza follows this line of thought when he states in IVP44Schol that the imagination struggles to perceive melancholy because of the diverse and variable causes that it involves. When Spinoza contrasts melancholy to the general affects that occupy the mind with only a single image, he suggests that melancholy entails such a multiplicity of causes that it is hard to conceptualize beyond its nominal definition, that is, as a thing that affects all the parts of the individual and that therefore always decreases an individual's power to strive.

Melancholy and cheerfulness, then, simply name affective states that cannot be easily conceptualized or imagined, but which always lead to a radical diminution or increase in an individual's power. To this extent, melancholy and cheerfulness do not appear to us as a fixed subject with a definable set of attributes, but rather as Drew Daniel theorizes early modern melancholy, namely, as an assemblage.

In his book, The Melancholy Assemblage: Affect and Epistemology in the English Renaissance, Daniel argues that in the early modern period melancholy did not function in the manner of a single substance or subject-like thing that arises from a single and easily determinable cause but, rather, as an assemblage. As Daniel argues, melancholy should be understood through the Deleuzo-Guattarian notion of assemblage and conceived as a multiplicity of extended and conceptual relations that are culturally and socially articulated and re-articulated. ${ }^{12}$ Because of melancholy's complex history and multiplicity of influences, its singularity as a fixed universal and describable affect should, he argues, be rejected in favour of its positing as something dynamic and plural - as a site of multiple relations grounded in a material assemblage of bodies (Daniel, 2013, p. 12). The word 'melancholy' becomes, for Daniel, a mere placeholder for the multiplicity of culturally mediated ideas and actions whose affective mixture is at once dynamic and changeable, whilst also being determinate and recognizable. To this extent, melancholy does not really exist in a fixed material form, such as the determinable humoral substance black bile, nor does it arise out of the intellectual isolation of the solitary philosopher, poet, or artist. And yet, despite this its idea, its presence remains in and is sustained through the materiality of bodies and their affective relations.

It is precisely because melancholy does not exist as a subject that, according to Daniel, it cannot be fixed at a particular point on the map of social ontology or intellectual

\footnotetext{
${ }^{12}$ For Deleuze and Guattari on the nature of assemblages, see Deleuze and Guattari, pp. 97-98.
} 
history (Daniel, 2013, pp. 239-240). Rather, melancholy is always constituted of relations between bodies; as an affect that continuously tethers bodies together in an activity of recognition and assimilation. Indeed, even the various representations of melancholy that are visible in Dürer's famous Melancholia I are less for Daniel an expression of fixed melancholic signs, and more about the relations between those received signs. In this regard, Daniel is interested less in the brooding angel herself than in the relations between the parts of her body, less with the angel and the objects of compass and purse than with the relations between the body and its surrounding objects, and less with any fixed meaning of Melancholia I than with the potential relations that might occur between the viewer and the etching (Daniel, 2013, p. 42). This latter relation between etching and viewer - the overall recognition and assimilation of melancholy by the viewer - is the most crucial relation, for it is this relation that proffers emulation and re-articulation of the diversity of what melancholy consists in and can be. Indeed, it is possible to say, according to Spinoza's theory of the affects, that Dürer's etching provides a site for a multiplicity of affects and their subsequent proliferation and sustenance via the imitation of the affects (see IIIP27).

To think of Spinoza's understanding of melancholy as an 'assemblage,' a particular kind of affect whose particularity and power resides in its multiplicity of causes, expressions, and historical representations, allows us to explain the normative language Spinoza uses to explain it. Just like the language of good and evil, melancholy's normativity should be explained in virtue of its utility to articulate a condition that is fundamentally changeable and, as such, unable to be easily represented under a single and encompassing image. In the same way that Spinoza treats good and evil, so melancholy is retained as an affect that indicates any assemblage of images and affects that radically reduce one's power to strive, and whose causes remain difficult to conceptualize. Here, the content of melancholy becomes secondary to the form that it takes, namely, a radical altering of the ratio of motion and rest of the individual who suffers it. Unlike pleasure and pain, whose forms can shift between an expression of joy and sadness, melancholy is always evil because it names a condition of being overwhelmed by a multiplicity of images that leads to a radical diminution of one's striving power. Once again, this is just to re-iterate melancholy's historical ubiquity whereby its content changes but the form it takes remains consistent: melancholy is everywhere agreed upon as to its harmful nature, but nowhere agreed upon as to its various causes or specific affective expressions. By affording melancholy a fixed value, Spinoza is not so much introducing normativity into his ethical theory as describing something that cannot be fixed on a social or ontological map, but that is nevertheless always recognizable in and to human beings as 'evil.' Melancholy is that thing which, as Jacques puts it, arises from many simples and is extracted from many experiences; it overwhelms and diminishes "absolutely" (IVP42Dem), and it is only this that makes it recognizable as melancholy. It is in this respect that Spinoza retains the word 'melancholy' and affords it with an objective value, for it names whatever results from an overabundance of images and affects and because of this is absolutely diminishing for the one who suffers it. For Spinoza, melancholy's normative status does not introduce into his theory of affects a set of pre-given affects that are always and in every situation 'evil,' but rather allows for a description of something that is everywhere recognized but nowhere fixed. Like good and evil, Spinoza retains a normative language to describe melancholy and cheerfulness for it allows us to give a name to that which is difficult to represent under a specific image or idea, but which is nevertheless always recognizable. 


\section{References}

Aristotle. (1984). The complete works of Aristotle: The revised Oxford translation, volume II

(J. Barnes, Ed.). Princeton University Press.

Bennett, J. (1984). A Study of Spinoza's Ethics. Cambridge University Press.

Burton, R. (1978). The anatomy of melancholy (J. Holbrook, Ed.). Rowman and Littlefield.

Camille, M. (1986). Walter Benjamin and Dürer's Melencolia I: The dialectics of allegory and the limits of iconology. Ideas and Production: A Journal in the History of Ideas, 5, 5879.

Daniel, D. (2013). The melancholy assemblage: Affect and epistemology in the English Renaissance. Fordham University Press.

Deleuze, G., \& Guattari, F. (1988). A thousand plateaus: Capitalism and schizophrenia (B. Massumi, Trans.). Continuum.

Freud, S. (2001). Mourning and melancholia. In J. Strachey (Ed. \& Trans.), The standard edition of the complete psychological works of Sigmund Freud Volume XIV (19141916) (pp. 243-258). Vintage.

Gatens, M., \& Lloyd, G. (1999). Collective imaginings: Spinoza, past and present. Routledge.

Gowland, A. (2006). The problem of Early Modern melancholy. Past and Present, 191(1), 77120.

Klibansky, R., Panofsky, E., \& Saxl, F. (1964). Saturn and melancholy: Studies in the history of natural philosophy, religion and art. Thomas Nelson and Sons LTD.

Lebuffe, M. (2009). The anatomy of the passions. In O. Koistinen (Ed.), The Cambridge companion to Spinoza's Ethics (pp. 188-222). Cambridge University Press.

Lucchesse, F. (2020). The mother of all prejudices: Teleology and normativity in Spinoza. Parrhesia, 32, 145-170.

Nadler, S. (1999). Spinoza: A life. Cambridge University Press.

Samuel Book 1, 16: 14-23, Holy Bible: King James Version.

Shakespeare, W. (1996). The complete works of William Shakespeare. Wordsworth Editions. Sharp, H. (2011). Spinoza and the Politics of Renaturalization. University of Chicago Press.

Spinoza, B. (1996). Ethics. In E. Curley (Ed. \& Trans.), A Spinoza reader: The Ethics and other works (pp. 85-265). Princeton University Press.

Spinoza, B. (2007). Theological-political treatise (J. Israel, Ed. \& Trans., M. Silverthorne, Trans). Cambridge University Press. 